International Journal of Nano Studies \& Technology (IJNST)

ISSN 2167-8685

\title{
Carbon Nanofibers from Electrospinning - A Promising Electrode Material for Energy Storage and
}

\section{Conversion}

\section{Zhang L}

Editorial

Joint School of Nanoscience and Nanoengineering, North Carolina Agricultural and Technical State University and the University of North Carolina at Greensboro, Greensboro, NC 27401, USA.

\section{*Corresponding Author:}

Lifeng Zhang

Joint School of Nanoscience and Nanoengineering,

North Carolina Agricultural and Technical State University and The University of North Carolina at Greensboro,

Greensboro, NC 27401, USA.

Tel: +1-336-285-2875

E-mail: lzhang@ncat.edu; 1_zhang2@uncg.edu

Received: December 28, 2013

Published: January 20, 2014

Citation: Zhang L. (2014). Carbon Nanofibers from Electrospinning - A Promising Electrode Material for Energy Storage and Conversion, Int J Nano Stud Technol, 03(01), 01-02. doi: http://dx.doi. org/10.19070/2167-8685-140004e

Copyright: Zhang $L^{\circ}$ 2014. This is an open-access article distributed under the terms of the Creative Commons Attribution License, which permits unrestricted use, distribution and reproduction in any medium, provided the original author and source are credited.

Innovative energy conversion and storage systems, e.g. rechargeable lithium ion batteries (LIBs), supercapacitors, solar cells, and fuel cells, are urgently demanded to meet increasing energy needs of modern society to fulfill newly emerging electric applications such as portable electronics, electric vehicles, and industrial power management [1]. The performance of these devices depends predominantly on the properties of their electrode materials. Carbon/graphite has been widely employed as electrode material because of its good chemical stability, thermal stability, and electrical conductivity. With recently widespread interest in nanomaterials, carbon nanotubes have been extensively used as component for both anode and cathode materials in energy conversion and storage systems because they possess not only common advantages of carbon but also high specific surface area and better charge transport properties [2,3]. However, carbon nanotubes often require delicate purification process to remove residue metal catalyst, which may have significant adverse effect on their electrochemical performance.

In recent years, making carbon fibers with diameters fall into submicron and nanometer range (termed as carbon nanofibers) has attracted growing attention. The production of carbon nanofibers falls into two categories: vapor growth and spinning. The approach of vapor phase growth, i.e. catalytic synthesis, has been investigated $[4,6]$ and graphitic carbon nanofibers are grown from carbon-containing gases by using metallic catalysts. Nonetheless, similar as carbon nanotubes, the carbon nanofibers from vapor growth are relatively short and difficult to be aligned, assembled, and processed into applications, not to mention their low prod- uct yield, expensive manufacturing equipment, and significant amount of catalyst residue. As a comparison, the rapidly developing technique of electrospinning provides a straightforward way to make continuous carbon fibers at nanometer scale (typically 50 $-500 \mathrm{~nm}$ ). Similar as conventional carbon fiber production, polyacrylonitrile (PAN) is the most often used precursor polymer for carbon nanofibers from electrospinning while other approaches are also available such as carbon nanofibers from carbide and lignin $[7,8]$. Driven by electrical force, the carbon precursor solution is ejected from spinneret during electrospinning and follows a binding, winding, spiraling and looping path in three dimensions and the jet in each loop grows longer and thinner, which is termed as "bending instability" $[9,12]$. With the evaporation of solvent, precursor nanofibers form and finally deposit on collector as a nonwoven mat. Following similar stabilization and carbonization procedures, the precursor nanofibers are successfully converted to carbon nanofibers with diameters approximately two to three orders of magnitude smaller than conventional carbon fibers [13, $14]$.

Compare to carbon nanotubes, carbon nanofibers from electrospinning have similar advantages as $1 \mathrm{D}$ carbon nanostructure and furthermore they are inexpensive, continuous, and relatively easy to be applied into applications. The adjustable electrical properties of carbon nanofibers from electrospinning have been evaluated and confirmed [15], which presented their potential as efficient electrode materials. An additional merit of carbon nanofibers from electrospinning is their ease of handling which is resulted from their intrinsic highly interconnected nanofibrous network structure due to "bending instability". The high interconnectivity and structural integrity of the carbon nanofiber products, i.e. mats, felts or membranes (different names but same meaning), not only allow the elimination of polymer binders or conductive fillers, which is commonly used in carbon electrodes, for better electrochemical performance, but also enable the resilience and flexibility of electrodes. The shape of carbon nanofiber mats from electrospinning can be freely tailored by cutting and will fit seamlessly in flexible electronic applications. In the past couple years, there is a rapid upsurge in research activities that devoted to carbon nanofibers from electrospinning for electrode materials in energy storage and conversion devices such as anodes/cathodes for Lithium ion batteries (LIBs), electrodes for electric double layer capacitors (supercapacitors), and counter electrodes for dyesensitized solar cells [16]. Undoubtedly this novel type carbon nanomaterial has demonstrated its promise as electrode material for high performance energy storage and conversion devices.

Furthermore, the original carbon nanofibers from electrospinning could not resolve all limitations that regular carbon electrodes 
face. In most recent years, researches of carbon nanofibers from electrospinning have been directed to even higher specific surface area and multiple-phase nanostructures to address a comprehensive improvement on electrochemical performance. It is envisioned that in the next few years carbon nanofibers from electrospinning are going to shine even greater luster as electrode material of choice in the field of energy storage and conversion.

\section{References}

[1]. Liu C, Li F, Ma L-P, Cheng H-M. (2010) Advanced materials for energy storage. Advanced Materials 22: E28-E62.

[2]. Liu X-M, Huang ZD, Oh SW, Zhang B, Ma P-C, Yuen MMF, Kim J-K. (2012) Carbon nanotube (CNT)-based composites as electrode material for rechargeable Li-ion batteries: A review. Composite Science and Technology 72: $121-44$.

[3]. Candelaria SL, Shao Y, Zhou W, Li X, Xiao J, Zhang J-G, Wang Y, Liu J, Li J, Cao G. (2012) Nanostructured carbon for energy storage and conversion. Nano Energy 1: 195-220.

[4]. Jong KPD, Geus, JW. (2000) Carbon nanofibers: catalytic synthesis and applications. Catalysis Reviews: Science and Engineering 42: 481-510.

[5]. Serp P, Corrias M, Kalck P. (2003) Carbon nanotubes and nanofibers in catalysis. Applied Catalysis A: General 253: 337-58.

[6]. Zou G, Zhang D, Dong C, Li H, Xiong K. (2006) Carbon nanofibers: synthesis, characterization, and electrochemical properties. Carbon 44: 828-32.
[7]. Presser V, Zhang L, Niu JJ, McDonough J, Perez C, Fong H, Gototsi Y (2011) Flexible nano-felts of carbide-derived carbon with ultra-high power handling capability. Advanced Energy Materials 1: 423-430.

[8]. Lai C, Zhou Z, Zhang L, Wang X, Zhou Q, Zhao Y, Wang Y, Wu X-F, Zhu Z, Fong H. (2014) Free-standing and mechanically flexible mats consisting of electrospun carbon nanofibers made from a natural product of alkali lignin as binder-free electrodes for high-performance supercapacitors. Journal of Power Sources, 247: 134-141.

[9]. Shin YM, Hohman MM, Brenner MP, Rutledge GC. (2001) Experimental characterization of electrospinning: the electrically forced jet and instabilities. Polymer 42: 9955-67.

[10]. Reneker DH, Yarin AL, Fong H, Koombhongse S. (2000) Bending instability of electrically charged liquid jets of polymer solutions in electrospinning. Journal of Applied Physics 87: 4531-47.

[11]. Shin Y, Hohman M, Brenner M, Rutledge G. (2001) Electrospinning: a whipping fluid jet generates submicron polymer fibers. Applied Physics Letters 78: 1149-51.

[12]. Hohman MM, Shin M, Rutledge G, Brenner MP. (2001) Electrospinning and electrically forced jets. I. Stability theory. Physics of Fluids 13: 2201-20.

[13]. Chun I, Reneker DH, Fong H, Fang X, Deitzel J, Beck Tan N, Kearns K. (1999) Carbon nanofibers from polyacrylonitrile and mesophase pitch. Journal of Advanced Materials 31: 36-41.

[14]. Inagaki M, Yang Y, Kang F. (2012) Carbon nanofibers prepared via electrospinning. Advanced Materials 24: 2547-66.

[15]. Hedin N, Sobolev V, Zhang L, Zhu Z, Fong H. (2011) Electrical properties of electrospun carbon nanofibers. Journal of Materials Science 46: 6453-6.

[16]. Zhang L, Aboagye A, Kelkar A, Lai C, Fong H. (2014) A review: carbon nanofibers from electrospun polyacrylonitrile and their applications. Journal of Materials Science, 49: 463-480. 